\title{
Trascendencia y secularización Una lectura teológica de la sociología de Peter L. Berger
}

\author{
FELIPE MARTÍN HUETE \\ Universidad de Granada (España) \\ felipem35@hotmail.es
}

\begin{abstract}
Resumen
La religión ha sido la institución más afectada por la pluralización de la realidad social. Esto es debido a que el papel simbólico y global de la religión, en tanto que institución integradora y significativa, queda socavado desde la plausibilidad de sus definiciones sociales de la realidad. La causa de esta situación se encuentra en que las personas viven - conciencia subjetiva - nuevos roles institucionales, nuevos esquemas interpretativos, nuevos valores y creencias. Sin embargo, si algo permanece invariablemente constante en la vida diaria de las personas es, afirma Berger, el temor a las situaciones marginales y a la anomia. Ni el proceso de secularización con sus universos simbólicos (filosofía diurna y teodiceas seculares), ni el resurgimiento religioso y global (desecularización público-política) han podido dar una explicación plausible y convincente de estos fenómenos que tanto afectan a la conciencia y a las identidades subjetivas de los individuos. En este sentido, y tras el fracaso de las anteriores cosmovisiones en su intento de dotar de sentido a la realidad y la vida ordinaria de las personas, Berger recurre a una nueva instauración del «nomos religioso»
\end{abstract}

Palabras claves: sociología, teología, teodicea, desecularización, secularización.

\section{Trascendency and secularization A Theological reading of the sociology of Peter $L$. Berger}

\begin{abstract}
Religion has been the institution most affected by the pluralization of social reality. This is because the overall symbolic role of religion as an institution inclusive and meaningful, is undermined from the plausibility of their social definitions of reality. The cause of this situation is that people livesubjetive consciousness-new institutional roles, new interpretative schemes, new values and beliefs. If something always remains constant in the daily lives of the people, says Berger, the fear of marginal situations and anomie. Neither the process of secularization with its symbolic universe (diurnal philosophy and secular theodicies) and the religious revival and global (desecularization publicpolitic) could give a plausible and convincing explication of these phenomena that affect the subjective consciousness and identity of individuals. In this regard, and after the failure of previous worldviews in their attempt to give meaning to reality and the ordinary life of people, Berger uses a new establishment of «nomos religioso».
\end{abstract}

Key words: sociology, theology, theodicy, desecularization, seculatization.

Doctor en Filosofía por la Universidad de Granada (España). Actualmente prepara su tesis doctoral en Sociología por la Universidad Pública de Navarra. 


\section{Introducción}

Si algo permanece invariablemente constante en la vida diaria de las personas es, afirma Berger, el temor a las situaciones marginales y a la anomia. Ni el proceso de secularización con sus universos simbólicos (filosofía diurna y teodiceas seculares), ni el resurgimiento religioso y global (desecularización público-política) han podido dar una explicación plausible y convincente de estos fenómenos que tanto afectan a la conciencia y a las identidades subjetivas de los individuos. En este sentido, y tras el fracaso de las anteriores cosmovisiones en su intento por dotar de sentido a la realidad y la vida ordinaria de las personas, Berger recurre a una nueva instauración del «nomos religioso». Este «nomos religioso» va a desempeñar las mismas funciones que ya desempeñó dentro de las sociedades pre-modernas y pre-secularizadas, esto es: 1) dar sentido, 2) evitar el caos anómico, 3) dominar la contingencia (situaciones marginales). Desde esta perspectiva, la religión se presenta como una nueva interpretación del mundo y como una construcción de creencias sobre las relaciones entre las fuerzas sobrenaturales y naturales, así como del entramado que da sentido al mundo, a la vida, al ser de los individuos. La religión volvería así, a desempeñar el papel estratégico de la 'construcción de mundos humanamente significativos'. Berger vuelve su mirada al modelo tradicional de sentido, a la concepción substantiva de la religión. Un modelo que se configuraba en torno al sentido que otorgaba la religión a los individuos, y que precisaba de los mecanismos de 'legitimación religiosa' y de 'alienación religiosa' como resortes de plausibilidad necesarios para soportar las embestidas de la anomia y de las situaciones marginales.

Partiendo del análisis de las diferentes crisis de sentido derivadas de la secularización y expuestas en su obra Modernidad, pluralismo y crisis de sentido, Berger (1997) centra su interés en encontrar mecanismos capaces de resolver los problemas causantes de las modernas crisis de sentido existencial. Esta empresa ontológico-epistemológica bergeriana no va a encontrar soluciones plausibles en la década de los noventa (recordemos que en esta década Berger desarrolla su 'desecularización públicopolítica'); sin embargo, a principios de este nuevo siglo, el autor ha apostado fuertemente por lo que él considera es el camino — acorde con las circunstancias actuales - para la instauración del 'nomos religioso'. Me refiero al proceso de la 'teologización de la conciencia'. Este modelo de plasmación actual del tradicional «nomos religioso» es desarrollado, fundamentalmente, en su obra Questions of faith (Berger, 2004). 
A partir de este nuevo modelo se puede apreciar cómo en Berger no se produce lo que muchos denominan un cambio de paradigma religioso, pues, podemos observar cómo en el transcurso que va desde el año 1969 ( $A$ rumor of angels), hasta el año 2004 (Questions of faith), en Berger se produce un anquilosamiento teológico. Es decir, el autor ha estado preso y pendiente, durante todos estos años de vigencia secularizadora, de dar respuestas al modelo del «nomos religioso tradicional». Por tanto, no podemos apreciar ruptura de paradigmas cosmovisionales religiosos en Berger, sino, más bien, recomposición y reestructuración de un modelo (modelo religioso tradicional) que ha sido fragmentado por otro modelo 'rupturista' (modelo secular) pero necesario para dar sentido al paradigma religioso bergeriano.

El problema de la crisis de sentido existencial en la actualidad, así como sus causas (recordemos, entre otras, la incertidumbre y la pérdida de lo 'dado por supuesto', debido al pluralismo y al relativismo, etc.) y sus posibles soluciones ya fue tratado, ampliamente, en el capítulo once de esta investigación, al desarrollar el concepto de desecularización como 'deconstruccionismo secular'. Sin embargo, lo que aquí intento plantear es cuáles han sido las consecuencias de esa crisis de sentido y cuáles las soluciones a nivel de las relaciones subjetivas (experiencias individuales) e intersubjetivas (axiológicas) de los individuos. Desde esta perspectiva, mi intención es desarrollar las tres posibles soluciones que Berger diagnosticó para salir de esta gravosa carga existencial de la modernidad: la confianza en los valores morales, la confianza en la fe, y la vía de la trascendencia. Partiendo de estos tres postulados restauradores, podemos apreciar que la intención de Berger no es otra que la de apostar por una 'desecularización de la conciencia' como ámbito de sentido, tras el fracaso de la 'desecularización pública-política' en la resolución social de la crisis de sentido, debido, fundamentalmente, al apego existente aún con el binomio secularización-modernización (recordemos el proceso de globalización).

Berger se da cuenta de que la crisis de sentido existencial trae consigo el replanteamiento fenomenológico del concepto 'vida y realidad cotidiana'. Es decir, el autor cree que este tipo de crisis se producen, esencialmente, por la falta de una 'legitimación religiosa' y de una 'configuración de valores supraordinales' que expliquen y regulen (estructuras de plausibilidad) la acción del individuo tanto en su vida cotidiana como en su relación con las realidades que trascienden esa vida cotidiana (teodicea). Es a partir de aquí, desde esta nueva revisión de las posibilidades actuales de la conciencia del individuo para dotar de sentido la realidad, donde el autor pretende instaurar de nuevo el 'nomos religioso' que el proceso de secularización eliminó en favor de la filosofía 
secular como 'universo de sentido'. La moderna crisis de sentido existencial estaría, pues, comprendida por la fragmentación que existe entre la vida cotidiana y la realidad extraordinaria. Por tanto, la superación de esta crisis estaría también comprendida y determinada por la posibilidad de encontrar mecanismos que restauren (a nivel subjetivo e intersubjetivo) esa fragmentación o ruptura a través de una recomposición del sentido existencial.

Desde la perspectiva de la sociología y la filosofía de la religión, el pensamiento bergeriano más reciente ha intentado salvar esta crisis de sentido existencial a través de dos procesos propios de una 'desecularización de la conciencia' y del 'nomos religioso' post-secular: $1^{\circ}$. Proceso de 'fiducialización' axiológica, mediante el cual el autor pretende resolver los problemas de los valores supraordinales que generan las crisis de sentido intersubjetivas, y que estaría muy ligado al postulado restaurador de 'confianza en los juicios morales incontrarrestables'; $2^{\circ}$. Procesos de 'teologización y teodiceización', mediante los cuales pretende superar las crisis de sentido existencial subjetivas. Estos procesos estarían relacionados con los postulados desecularizadores de 'confianza en la fe' y 'la vía de la trascendencia'.

\section{Las influencias teológicas}

Son tantas las influencias que se manifiestan en la elaboración del pensamiento de Peter L. Berger, que hacen bastante difícil la labor de determinar cuál es su pensamiento originario y propio. Esta situación va a plantear una doble posibilidad de aproximación a su pensamiento: Por un lado, las numerosas influencias acontecidas en Berger, hacen que su obra goce de una sincrética riqueza intelectual, de una consistente congruencia teórica, y de un fuerte virtuosismo de síntesis metodológica que se manifiesta en su capacidad de acomodar todas estas 'deudas' intelectuales a sus específicos campos epistemológicos —sociología del conocimiento, sociología de la religión, teología, ética, fenomenología, política, etc. Por otro lado, debido a esta carga deudora, el pensamiento de Berger ha sido muchas veces criticado de ecléctico, de ser demasiado elemental y de ser poco original (Hunter, 1984). Todas estas acusaciones se basan en esa - y nunca oculta- capacidad que Berger manifiesta a la hora de utilizar el pensamiento de cualquier autor, si cree convenientemente utilizarlo en el desarrollo de sus propias construcciones teóricas.

Dentro de las influencias teológicas en el pensamiento de Berger hay que destacar, principalmente, a dos autores: F. Schleiermacher y Simone 
Weil. Estas influencias quedan reflejadas en palabras del propio autor, cuando sobre Schleiermacher y su teología afirma: «Me siento como en casa en el seno del protestantismo liberal y conecto (en actitud, aunque no en el contenido) con Friedrich Schleiermacher, porque esta tradición encarna justamente el punto de equilibrio entre escepticismo y afirmación que define, a mi entender, el único camino aceptable para poder ser cristiano sin tener que emigrar de la modernidad» (Berger, 2003: 7). De igual modo, sobre Weil afirma: «Me inclino por elegir un testimonio genuinamente moderno, el de Simone Weil (1909-1943), la filósofa de idiosincrasia francesa a quien la norteamericana Leslie Fiedler, admiradora suya, describía muy acertadamente como 'una santa en tiempos de alienación’» (Berger, 2003:7), y también: «El punto de partida (de Weil) es útil, al menos para los que se encuentran en 'tiempos de alienación'... El punto de partida de Weil es también útil incluso para quienes no son capaces de acompañarla durante todo el viaje» (Berger, 2003:7-8).

La influencia teológica de Schleiermacher es una de las más evidentes y más determinantes en su pensamiento y, aunque el mismo Berger señala que no hay herencia respecto a los contenidos del autor alemán, son muchos los trasvases que se pueden apreciar en su obra. Si dentro de la sociología del conocimiento hemos señalado que Berger es deudor, fundamentalmente, de Alfred Schütz, y dentro de la sociología de la religión es deudor de Durkheim y, principalmente, de Max Weber; dentro de su pensamiento teológico podemos señalar, sin lugar a dudas, a Schleiermacher. Hasta tal punto se llega a identificar a Berger con el autor alemán del siglo XVIII que en algunos sectores del pensamiento actual se considera que la obra de Berger constituye una de las llamadas 'teologías del mundo', que no son más que nuevas ediciones del pensamiento de Schleiermacher.

De Schleiermacher, Berger hereda su tradición teológica liberal. Esta teología, que forma parte de la historia del protestantismo, ha sido tachada de fomentar un falso optimismo histórico que se fundamenta no en la realidad sino, más bien, en la 'otra realidad', en lo trascendente que

La teología del mundo o teología política sitúa las razones de la fe no en el horizonte de la razón científico-instrumental o técnica, sin sujeto ni historia, ni en el de la razón pura, que ni siente ni padece, sino en el de la razón práctica en su dimensión pública y subversiva, que cuestiona la sociedad burguesa y se traduce en solidaridad con las víctimas. La persona creyente acredita la verdad de la fe a través de una praxis histórica transformadora. Es un modelo ampliamente compartido por la teología europea de los últimos 50 años (Moltmann, Metz, etc.) y respetado en buena medida por la teoría crítica de la sociedad (véase Juan José Tamayo-Acosta, El País, Madrid, Jueves Santo, 12 de abril de 2001). Ver también: Metz (1970). 
se hace presente en lo inmanente. También, esta teología ha sido tachada de ser una teología de la 'ausencia de Dios', donde éste es reemplazado por el protagonismo antropológico.

El pensamiento teológico bergeriano, desarrollado en obras como The sacred canopy (1967), A rumor of angels (1969), A far glory (1992) y Questions of faith (2004), asume estas dos posibilidades y a partir de ellas construye su teología inductiva. Esta teología inductiva, partiendo de ese protagonismo antropológico que postula la teología liberal de Schleiermacher, pretende llegar a la trascendencia a partir de la experiencia de la vida cotidiana de los individuos, conformando una especie de antropología teológica. Esta perspectiva bergeriana pretende conciliar la sociología fenomenológica de la realidad de la vida cotidiana, de la experiencia de vida, con la teología. Se trataría de hacer teología no desde la trascendencia sino desde la inmanencia, pues como afirma Berger, «la trascendencia está detrás de toda inmanencia, solo hay que descubrirla». Así pues, el discurso de Dios está presente dentro de la teología liberal bergeriana, lo único que cambia es el acceso a él. Por otro lado, el optimismo histórico del que se acusa a la teología de Schleiermacher es asumido en Berger (2004) en obras como Questions of faith. En esta obra Berger retoma el discurso anterior de $A$ rumor of angels (1969) y desemboca en una teodicea escatológica como salida al 'problema de la teodicea' y a la crisis actual de sentido. Existen numerosas referencias en la obra de Berger que reflejan el mencionado trasvase de pensamiento de un autor a otro. En este sentido, especificar todas esas influencias sería una empresa harto difícil. A modo de ejemplo, es preciso indicar que otra de esas influencias fundamentales que aparece en la obra religiosa bergeriana y que también es heredado del autor alemán es el denominado 'sentimiento de dependencia' (también heredado de Feuerbach al desarrollar el problema de la alienación) que Berger asume y, después de darle una carga teológico-política de carácter neoconservador, deriva en una necesidad de orden nómico sagrado. A través de esta corriente de pensamiento teológico liberal, Berger entra en contacto con otros autores como R. Bultmann, Von Harnack, K. Heim, J. Hick, etc.

Las influencias de Simone Weil se convierten en la obra de Peter Berger en una fuente inagotable de recursos teológicos. Este pensamiento se presenta en su obra bergeriana de dos formas: 1) de forma implícita, pues, para el conocedor del pensamiento de ambos autores no resulta difícil ver el trasfondo weilinano en la obra de Berger; 2) de forma explícita, ya que Berger hace uso del pensamiento de Weil no en todas sus obras pero sí en sus obras con connotaciones teológicas, por ejemplo, A rumor of angels (1969), A far glory (1992) y Questions of faith 
(2004). Estas influencias explícitas se hacen presentes en tres ámbitos cognoscitivos de Berger:

1) En Sociología de la religión, donde recoge, principalmente, dos elementos weilianos:

$1^{\circ}$. La construcción social del 'yo solitario'. Berger considera que Simone Weil es el paradigma del creyente solitario en la situación religiosa moderna (Berger, 1992: 103).

$2^{\circ}$. El concepto de 'vocación' socio-religioso. Berger parte de la obra de Simone Weil para definir el concepto de 'vocación'. A partir de este concepto, Berger desarrolla dos versiones del mismo, de cara a poder establecer un compromiso social con las instituciones religiosas:

-Una 'vocación dogmática': consistente en permanecer en la propia comunidad de origen, aunque dicha comunidad se haya convertido en un lugar poco atractivo (Berger, 1992: 190);

-Una 'vocación anatémica': consistente en desempeñar, como la autora francesa, un rol de solitario e independiente.

Estos dos conceptos serán utilizados por Berger a la hora de desarrollar su teoría de las adaptaciones o atrincheramientos de las creencias individuales y sociales ante el problema de la secularización.

2) En Teología, donde las influencias weilianas dentro de esta disciplina quedan plasmadas en cuestiones que son esenciales en el desarrollo teológico bergeriano. Entre estas aportaciones podemos señalar: El concepto de Dios, la discusión sobre Dios y el problema del sufrimiento, la cristología 'ascendente' y 'descendente', la crítica social de la Iglesia como institución omnipotente, el sincretismo, el ecumenismo y el diálogo interreligioso, el misticismo, etc.

Dentro de estas aportaciones teológicas weilianas, es importante señalar que Berger se identifica mucho con la crítica social de Weil a la Iglesia como institución omnipotente y universal. Berger asume esta postura y elabora un discurso en el cual hace una crítica a la Iglesia debido, fundamentalmente, a su anclamiento histórico y a su escaso afán de trascender la realidad cultural en la que se encuentra (pasividad social). Berger hace suyos los planteamientos weilianos y considera que es necesaria una «cierta relativización del concepto Iglesia» (Berger, 2003: 190) que considere una revisión de las pretensiones absolutistas a raíz del carácter relativista de la realidad. Lo que Berger pretende decir es que la Iglesia debe adaptarse a la realidad social que viene marcada por las necesidades históricas y sociales. Es decir, Berger se niega a otorgar un carácter absoluto a la Iglesia institucional y considera que lo único que da un carácter de fiabilidad y ciertas estructuras de plausibilidad a la actual 
Iglesia es que «sigue dando testimonio del núcleo central del mensaje cristiano» (Berger, 2003:140). El autor utiliza como ejemplo contrario el protestantismo, en el que hay una actitud de libertad respecto a todas las formas religiosas de la historia, una independencia identitaria respecto a las instituciones a las que relativiza, y una necesidad de trascender y de buscar.

3) En Teodicea cristiana, donde as influencias en esta disciplina se enmarcan dentro de la denominada teodicea dualista. Esta teodicea ha sido el marco en el que Berger se ha movido antes de desarrollar su más reciente teodicea escatológica. Dentro de esta teodicea dualista weiliana, los elementos más decisivos y conflictivos en la elaboración posterior de la teodicea escatológica de Berger han sido, entre otros:

La relativización de los fenómenos anómicos en un 'otro mundo' u 'otra realidad'.

El maniqueísmo ético. Donde el mal es igual a las fuerzas malignas o negativas y el bien equivale a las fuerzas positivas.

La búsqueda redentora del individuo.

La identificación de la 'anomia' con el universo empírico, inacabado, al contrario que el nomos, que se configura en la lejanía del universo empíricamente determinado.

La plausibilidad del monoteísmo para explicar el problema del mal. 'El mal es constitutivo del mismo Dios'. Ruptura frente a la antropodicea kantiana.

Las construcciones soteriológicas no susceptibles de desmentido empírico. Dios (bien) contrapuesto al mundo (mal).

Pero, sin lugar a dudas, la gran aportación de la teodicea weiliana a la teodicea de Berger ha sido la 'teodicea del sufrimiento' o 'teología de la cruz'. Esta teología de la cruz es una vía doble de acceso: de Dios al hombre y del hombre a Dios a través de la desdicha (sufrimiento físico y moral en Weil) y el sufrimiento (redención según Berger). En el pensamiento de Simone Weil, estas dos vías son: la vía ascendente (acceso del hombre a Dios a través de la negación del 'yo'), y la descendente (de Dios hacia el hombre a través de la voluntad divina). Berger va a aprovechar estas dos vías de acceso: por una lado, una vía descendente que va de Dios al hombre, pues, según Berger, es Dios quien se manifiesta y elige al hombre (herencia de Schleiermacher y su sentimiento de dependencia hacia el absoluto); por otro lado, una vía ascendente, pues por medio de las experiencias antropológicas (teología de la inmanencia) el hombre descubre a Dios. La teodicea bergeriana, recoge todas estas influencias weilianas y concluye en su teodicea 
escatológica, según la cual «Dios sufre junto con el mundo y Dios será en el futuro juez de este mundo» (Berger, 2003: 40).

\section{Religión e identidad socio-existencial: la necesidad de legitimaciones religiosas}

La religión es considerada como un elemento clave en la configuración de identidades sociales singulares, puesto que proporciona elementos para la diferenciación entre el 'nosotros' y 'los otros'. Berger apuntaba que la identidad personal y social se construye a través de la internalización de la realidad constituida. Se llega pues, a tener una identidad social mediante un proceso de socialización, que es también de identificación. En él se aprende la cultura y los pertinentes significados culturales, así como las funciones y posiciones sociales. Pero no sólo se aprende a vivir de acuerdo a las normas, los usos y los estilos de la sociedad, sino que las personas se identifican con los significados socialmente aceptados, y son de este modo moldeados por ellos.

Berger indica que este modo de la relación del hombre con sus creaciones es muy importante, pues si la socialización no conduce a la internalización de los significados considerados más importantes por la sociedad, ésta no persistiría en el tiempo. Berger señala que tales conceptos confluyen, pues la integración equivale a la identificación del individuo con sus realidades en la experiencia cotidiana, mediante el reconocimiento o identificación con los otros significativos. De esta forma, la identidad se legitima totalmente si la situamos en el contexto del universo simbólico ${ }^{2}$. La identidad se hace más profunda y estable cuando no son los demás seres humanos (otros significativos) los que identifican a una biografía individual, sino que es una significación cósmica, en el sentido de seres suprahumanos y valores supraordinales, los que hacen posible la autoidentificación. La otra forma de identidad, la que depende de las relaciones del individuo con los otros significantes (seres humanos), es considerada por Berger como una identidad subjetiva precaria, debido a que la propia naturaleza de la socialización hace que esta pueda variar o desaparecer.

2 Berger encuentra la mayor etapa de la organización simbólica en lo que denomina el universo simbólico, es decir, «cuerpos de tradición teórica que integran diferente provincias de significado y abarcan el orden institucional en una totalidad simbólica» (Berger \& Luckmann, 1966: 71). Otra definición bergeriana es: «El universo simbólico de una sociedad es un cuerpo de tradición que integra un gran número de definiciones de la realidad y presenta el orden institucional al individuo como una totalidad simbólica» (Berger \& Luckmann, 1966: 68). 
Nuestro autor hace constar que estas legitimaciones religiosas tienen una serie de funciones según las cuales pretenden instaurar una estructura de plausibilidad fundamentada en la concepción del microcosmos-macrocosmos, conforme a la relación existente entre la sociedad y el cosmos, entendido como universo sagrado. Esto hace posible las «reiteraciones miméticas de las realidades cósmicas» (Berger, 1967: 38), según las cuales, la representación de los significados humanos deben de ser considerados como imitación de los significados divinos, dando lugar a la dicotomía entre lo temporal (humano) y lo inmortal y eterno (divino). Berger caracteriza a estas legitimaciones religiosas como interpretaciones del orden social en términos de un orden sagrado (universo simbólico), que se conforman frente al desorden de una realidad que puede ser devorada por las pesadillas de la otra realidad sombría, la anomia:

Ir contra el orden de la sociedad es siempre correr el riesgo de deslizarse en la anomia. Pero ir contra el orden de una sociedad religiosamente legitimada es además chocar con las fuerzas primordiales de la oscuridad. Negar la realidad tal como es socialmente definida es correr el riesgo de caer en la irrealidad, porque es casi imposible sostener a la larga, solo y sin apoyo social, unas definiciones contrarias al mundo. Cuando la realidad tal como es socialmente definida ha llegado a ser identificada con la realidad última del universo, su negación sería el mal y la locura. Aquel que formulase esta negativa correría el riesgo de entrar en lo que se podría llamar una realidad negativa (Berger, 1967: 38).

Berger asigna otras funciones a las legitimaciones cósmico-religiosas, y entre ellas se encuentra, en primer lugar, la de actuar como recordatorio de los conceptos tradicionales incorporados a la cultura y sus propias instituciones; en segundo lugar, la función de establecer una dialéctica entre la actividad y la ideación religiosa. Es decir, hacer ver que tales legitimaciones religiosas son producto de la necesidad del propio desarrollo de la actividad, en cuanto productos de la conciencia de los individuos, y no como meras creaciones teóricas en las que los individuos son meros agentes pasivos. Tales legitimaciones religiosas nacen de la necesidad humana de universos simbólicos supraordinales, que hacen posible la auto-identificación. La otra forma de identidad, la que depende de las relaciones del individuo con los otros significantes (seres humanos) es, como ya se señaló, una identidad subjetiva precaria, debido a que la propia naturaleza de la socialización hace que ésta pueda variar o desaparecer. En sentido colectivo, el universo simbólico también 
ordena la historia. Mediante la explicación del pasado y la interpretación del futuro, el presente gana significación.

Berger señala otras funciones propias de las legitimaciones religiosas; una de ellas es definida siguiendo a E. Durkheim, es decir, "como capacidad para mantener la realidad de este mundo socialmente construido dentro del cual, los hombres existen y su vida de cada día transcurre» (Berger, 1967: 42) ${ }^{3}$. Pero quizás, la función más importante que desempeñan las legitimaciones religiosas en cuanto universos simbólicos, consiste en la 'integración' en un nomos englobador de todas las situaciones marginales ${ }^{4}$ que pueden dar lugar al terror de la anomia ${ }^{5}$. Para el autor, la forma con que estas legitimaciones religiosas se enfrentan a tal anomia, es precisamente estructurando todas las realidades concebibles dentro del mismo universo simbólico que abarca la totalidad de la experiencia biográfica del individuo, de forma que, esta última realidad pueda retener su calidad prominente, por la que se vuelve a la realidad de la vida cotidiana como una realidad aceptada comúnmente.

Esta integración, tanto de las situaciones marginales (marginal situations) como de otros significados discrepantes dentro de la vida cotidiana, es debida al proceso de 'reflexión', que posibilita que todos los sectores discrepantes de la vida cotidiana puedan confluir siempre en referencia al orden establecido. En este proceso de integración, llevado a cabo por las legitimaciones religiosas, es donde la religión adquiere una nueva función, a saber, la de 'aplicación aniquiladora de los mecanismos conceptuales inherentes y marginales al universo simbólico'. Berger lo define diciendo que «la religión mantiene la realidad socialmente definida legitimando las situaciones marginales en términos de una abarcante realidad sacra. Ello permite al individuo que pasa por estas situaciones

3 La legitimación religiosa, afirma Berger, «permite una confrontación con la época en que se vive desde una perspectiva que trasciende dicha época y la muestra en sus auténticas proporciones» (Berger, 1969: 185).

Las influencias que Berger recibe en la concepción del término «marginal situations» (Berger, 1967: 42), derivan de K. Jaspers y Schütz. Más concretamente, de Alfred Schütz, Berger incorpora una concepción del 'orden social' según la cual, éste depende de una decisión colectiva de no poner en discusión una amplia gama de supuestos subyacentes a la experiencia cotidiana, con el fin de evitar la amenaza incipiente de la anomia (situaciones marginales), que se da en el hecho de poner en duda el orden establecido. La religión afirma la realidad social definida en las situaciones marginales de la vida diaria de la sociedad. Las legitimaciones religiosas están siempre presentes en las situaciones marginales de la existencia humana: muerte, guerra, desastres naturales, agitación social.

Berger basa su argumentación en la significación que el término 'anomia' adquiere en los análisis de E. Durkheim. 
continuar 'existiendo' en el mundo de su sociedad - no 'como si nada hubiera ocurrido'-, lo cual en las situaciones marginales extremas sería psicológicamente demasiado difícil, sino en el convencimiento que aún estos sucesos o experiencias ocupan un lugar en un universo que tiene sentido» (Berger, 1967: 44). Esta concepción de la religión deriva de concebir a las situaciones marginales como exteriores "éxtasis' ${ }^{96}$ a la realidad socialmente aceptada. Berger desarrolla, como ejemplo, la situación marginal que constituye la muerte ${ }^{7}$.

\section{Alienación, teología de la inmanencia y fundamentación antropológica}

Según Berger, la receta fundamental de tal legitimación religiosa es la transformación de los productos humanos en facticidades suprahumanas y no humanas: «El mundo hecho por los hombres es expuesto en términos que niegan esa producción humana» (Berger, 1967: 89). Berger establece la relación existente entre la religión y la alienación, pues, según él, la religión históricamente presenta un poder alienante e inherente en la construcción y conservación del mundo, y en la alienación de lo humano en sí mismo.

Encontramos en Berger un método pannenbergiano ${ }^{8}$, según el cual, por un lado, el autor aceptaría la realidad de tales proyecciones religiosas orientadas hacía una alteridad; pero, por otro lado, admitiría la 'mediación antropológica', pues «los seres humanos proyectan sus significaciones en el universo que les rodea» (Berger, 1967: 89). De este modo, siguiendo a Pannenberg, Berger, considera que esta teoría de la proyección tiene un doble aspecto: uno positivo, en donde se

6 Berger piensa que «la sociedad nos proporciona cavernas tibias y razonablemente cómodas en las cuales podemos acurrucarnos con nuestros compañeros, tocando los tambores que ahogan los aullidos de las hienas que se encuentran en las tinieblas circundantes. El 'éxtasis' es el acto de salir, en solicitud, de las cavernas para enfrentarse a la noche" (Berger, 1989: 461-468).

Tanto Berger como otros destacados sociólogos (Weber, Yinger, etc.,) coinciden en señalar que la religión desempeña una función social, en la que una de sus principales funciones por medio de sus manifestaciones externas (ceremonias, tiros religiosos) ha sido, desde sus orígenes, la de ofrecer explicaciones y legitimaciones a los sufrimientos humanos. Entre estas situaciones de inmenso sufrimiento se encuentra: la enfermedad, dolor, soledad, miseria, abandono y sobre todo la muerte.

8 Pannenberg (1976) intenta justificar el carácter científico de la religión, y acaba justificando su racionalidad en la capacidad de la religión para fundar la experiencia del sentido o del significado de la totalidad del universo. Para más información sobre Pannenberg, ver Fraijó (1986). 
establecería que tal teoría de la proyección no es más que el propio interés humano en buscar un significado y un sentido ante el terror de la anomia. Es decir, que la alineación consistiría en una actitud antropológicamente necesaria para el hombre ante el extrañamiento de una realidad social frágil y necesitada de estabilidad y continuidad que puede configurar la realidad. Es decir, sería una configuración de la realidad en la que se establecería una "teoría de los deseos», pues, como señala Freud: «Nos decimos que sería muy bello que hubiera un Dios creador del mundo y providencia bondadosa, un orden moral universal y una vida de ultratumba, pero encontramos harto singular que todo suceda así tan a medida de nuestros deseos» (Freud, 1981: 2.979). El segundo aspecto es el negativo, y consistiría en ese 'darse cuenta' de que todo no es más que una ilusión ${ }^{10}$, porque a esa alteridad pretendida no le corresponde ninguna realidad extramundana. En este sentido, Berger coincide con Pannenberg en señalar los límites de una argumentación antropológica para probar esa alteridad. Es decir, ambos coinciden en señalar que: 1) tales proyecciones religiosas alienantes están arraigadas constitutivamente en la naturaleza del ser humano, es decir, serían antropológicamente necesarias; 2) tales proyecciones religiosas presentan un poder alienador para la experiencia del mundo.

Lo interesante de esta argumentación consiste precisamente en señalar la polaridad que subyace en la sentencia categórica bergeriana: 'La alienación es antropológicamente necesaria'. Hay autores, como Baum, que plantean una serie de objeciones a la teoría de la alienación propuesta por Berger. Éstos no consideran viable fomentar una imaginación que considere tal alienación antropológicamente necesaria; por el contrario, prefieren analizar los procesos sociales desde la perspectiva de la libertad como el destino del hombre. Frente a ellos, Berger en su obra Questions of faith. A skeptical affirmation of christianity (2004), señala que «la libertad presupone que no estoy simplemente siguiendo las reglas y creencias de

9 «El deseo, es verdad, expresa una carencia, una negación; pero conlleva también la voluntad de superación. 'El deseo es un esclavo de la necesidad, pero un esclavo con la voluntad de superación; un hijo de la pobreza, de la penuria, pero de la pobreza que es madre de la apetencia, del amor'. Ahora bien, si la religión o la teología se imaginan realizando el deseo en la divinidad, Dios recibe, pues, su esencia y 'existencia' no de lo que el hombre ya tiene, sino de lo que desea. La unidad, por consiguiente, de proyección y deseo es Dios en tanto que expresa aquello que quiere ser el hombre» (Rubio Ferreres, 1987: 89).

10 Baum tiene una concepción particular de lo que para Berger representa la ilusión: «Para él, la alienación consiste en la ilusión de que los procesos sociales son realidades fijas e inmutables; la alienación consiste en que sea reprimida la verdad de que la sociedad se reduce a que los individuos hagan unidos las cosas, lo que la hace básicamente frágil e inestable» (Baum, 1980: 125). 
mi entorno. Esto significa que yo estoy relativamente alienado de mi entorno» (Berger, 2004: 81-82). Siguiendo a Arnold Gehlen —quien le influenció en este tema- Berger considera que alienación y libertad son dos caras de la misma moneda. Por otro lado, encontramos autores, como Pannenberg, que basándose en las consideraciones freudianas y feuerbachianas, hacen posible empatizar con la concepción bergeriana antes propuesta. Desde esta última perspectiva, Berger asume plenamente la concepción hermenéutico-crítica de Feuerbach y los análisis fenomenológicos de autores tales como R. Otto, Durkheim, etc. De esta forma vamos a encontrar similitudes conceptuales definitorias en estas diferentes concepciones cognoscitivas.

Por ejemplo, la definición bergeriana de la religión en cuanto alienación religiosa: «Es la transformación de los productos humanos en facticidades suprahumanas y no humanas» (Berger, 1967: 89), deriva de la concepción feuerbachiana del concepto de religión, según el cual, «la religión es la conciencia de lo infinito; es y sólo puede ser la conciencia que el hombre tiene de su esencia, no finita y limitada, sino infinita. (...). Es la conciencia de lo infinito, el hombre consciente tiene por objeto la infinitud de su propia esencia» (Feuerbach, 1975: 52). De igual modo, Berger considera que la religión lleva a cabo el proceso de alienación, por medio de la extrapolación sistemática a lo 'totalmente otro' y a la presencia en la realidad de seres ajenos ${ }^{11}$ al mundo humano, a 'otros mundos' fuera del alcance empíricamente humano. De nuevo se aprecia aquí la influencia que las concepciones fenomenológicas de la religión llevan a cabo en el pensamiento bergeriano, principalmente en las pretensiones que Berger tiene de postular la revelación de un espacio sagrado que permita al hombre orientarse en la homogeneidad caótica, así como la irrupción de lo sagrado (seres ajenos al mundo humano).

Berger pretende presentar la alienación como una 'esencia antropológica' a la vez que una necesidad antropológica. Para ello, como señalamos anteriormente, el autor utiliza el método hermenéutico de autores como Feuerbach, Bloch, Pannenberg o Freud entre otros, con el que puede llevar a cabo una depuración cognoscitiva de la alienación en cuanto legitimación religiosa como 'verdad antropológica'. Berger pretende establecer una reducción antropológica de la alienación religiosa, llevando a identificar la 'esencia de la alienación' como una

11 «La esencia de la experiencia religiosa es la sumisión a poderes superiores a nosotros. Jung declara que la religión 'es la observación cuidadosa y escrupulosa de lo que Rudolph Otto llamó acertadamente el numinosum, es decir, un efecto o existencia dinámicos, no causados por un acto arbitrario de la voluntad. Por lo contrario, se apodera del sujeto humano y lo dirige, convirtiéndolo así más bien en su víctima que en su creador» (Fromm, 1967: 31). 
'verdad antropológica necesaria'. Tal es esta necesidad alienadora en el hombre, que Berger considera que la posibilidad de desalienación, es simultánea a la desintegración de la estructura de plausibilidad del orden institucional. De este modo, Berger intenta configurar un marco de sentido emancipador respecto a la alienación religiosa, al pretender reducir -igual que Feuerbach-y disolver el mundo religioso, reduciéndolo a su base terrenal (Marx, 1979: 160). Tal es la reducción antropológica de lo sobrenatural que se ha llevado a cabo en la modernidad, que Berger considera que la trascendencia se ha reducido a meros 'signos de trascendencia' y que estos a su vez se han reducido a lo que denomina 'rumor de ángeles' digno de poco crédito de plausibilidad. (Todo esta problematización será desarrollado más adelante, al analizar la teoría de la secularización y de la desecularización bergeriana).

$\mathrm{El}$ autor observa que una de las funciones alienantes de la religión consiste, precisamente, en la mistificación, pues «la religión mistifica las instituciones humanas refiriéndose a ellas como algo dado por encima y más allá de su existencia empírica en la historia de una sociedad» (Berger, 1967: 90). De la misma forma, Marx postula también esta mistificación de la religión, en tanto que producto de la alienación impuesta en la vida humana. Es decir, Marx considera que esta mistificación se produce en la medida en que «las personas incapaces de encontrarse a sí mismas y ser felices en el mundo al que pertenecen tienden a crearse otro mundo en el que se manifestaría su auténtico destino» (Baum, 1980: 43). Desde esta perspectiva, la religión es claramente 'falsa conciencia', pues su legitimación apela a un 'algo dado más allá de su existencia empírica', para desde ahí configurar el ordenamiento social; la religión legitima las instituciones sociales otorgándoles un status ontológico, a través del cual quedan situadas en un marco de referencia cósmico y sagrado. En esto consiste el proceso de mistificación.

Berger señala que el elemento fundamental que identifica la religión con la alienación consiste, precisamente, en la extrapolación inherente y 'necesariamente constitutiva' que lleva a identificar el mundo empírico de 'aquí abajo', con su correspondencia 'allá arriba'. Es la 'otra realidad', la semilla alienadora de la religión, según Berger. En este sentido, se verá más adelante cómo el autor presenta y establece una solución al problema, mediante la postulación de una 'teología de la inmanencia', fundamentada esencialmente en las capacidades y potencialidades antropológicas del hombre, así como en un ir dejando la 'otra realidad' reducida a lo Berger llamará 'signos de trascendencia'. El autor observa aquí la reminiscencia unitaria de las antiguas e intrínsecamente necesarias relaciones existenciales, entre lo empíricamente humano y la 'otra realidad'. Por tanto, se pretende con ello llegar a una configuración social 
en la que la religión corresponderá a la esencia humana en la medida en que, consciente de la finitud, se deje mediar por ésta y se deje negar y asimilar por el hombre finito, aunque al mismo tiempo surja de nuevo con un nuevo ideal, pero siempre como negación determinada o satisfacción real respecto a la necesidad y aspiración concreta, histórica; de lo contrario, se queda en una universalidad o indeterminación no mediatizable, y por tanto, desconectada de la esencia y la vida humana. Para ello, hay que romper con la concepción de la religión como instrumento, poderosamente eficaz, para el mantenimiento de esta falsa conciencia.

Berger señala que hay que tener muy en cuenta tres consideraciones esencialmente definitorias y constitutivas: $1^{\circ}$ ) Debido al proceso de mistificación de la religión -que refuerza la ilusoria autonomía del mundo humanamente producido-, la interiorización social lleva consigo el misterioso poder atribuido por sus legitimaciones sociales. Es decir, el individuo en sí es un elemento existencialmente identificativo de lo sagrado, en tanto que su realidad se funda directamente en el realissimum suprahumano propuesto por la religión; $2^{\circ}$ ) La esencia de esa falsa conciencia alienadora consistirá en la configuración impositiva de una «inexorabilidad ficticia al mundo humanamente construido» (Berger, 1967: 95), donde, según Berger, la principal consecuencia es la falsa aprehensión de la historia y de las biografías empíricas, como basadas en realidades supraempíricas; $3^{\circ}$ ) Las significaciones proyectadas por la actividad humana se fundamentan en 'otra realidad' en términos de una 'total dependencia'"12 , es decir, en términos de una necesidad interna que ejerce un dominio divino en el hombre (Scheleiermacher, 1990: 4). «A través de la alteridad de lo sagrado la alienación del mundo que el hombre construye termina de ratificarse del todo» (Berger, 1967: 96). Berger vuelve a introducir en esta problemática el elemento del masoquismo teodiceico como actitud relacionada con esta dependencia en virtud de una necesidad de significación establecida en el encuentro con lo sagrado, con la 'otra realidad' de la conciencia religiosa.

Desarrollado el dualismo religión-alienación en todas sus implicaciones metodológicamente legitimadas, Berger centra su interés en deshilvanar la posibilidad de que la misma desalienación sea religiosamente legitimada; es decir, el autor pretende mostrar cómo la

12 Esta total dependencia deriva, según Feuerbach, del sentimiento de finitud del sujeto, puesto que la esencia de la religión se presenta como expresión del 'sentimiento de dependencia' cuyo principal estímulo es la conciencia de la muerte. «El sentimiento de dependencia sobrevalora a 'aquél' de quien se depende. En último análisis, la dependencia de mi ser de otro se resuelve en la dependencia de mi persona respecto de mis deseos, intereses y pasiones» (Rubio Ferreres, 1988: 88). 
religión, que hasta ahora era fuente de alienación (Hegel), así como un producto de alienación (Marx), posee también los elementos potencialmente necesarios para invertir el proceso, para pasar de la alienación a la desalienación.

\section{Conclusiones}

La religión ha sido la institución más afectada por la pluralización de la realidad social. Esto es debido a que el papel simbólico y global de la religión, en tanto que institución integradora y significativa, queda socavado desde la plausibilidad de sus definiciones sociales de la realidad. La causa de esta situación se encuentra en que las personas viven - conciencia subjetiva- nuevos roles institucionales, nuevos esquemas interpretativos, nuevos valores y creencias. La religión se transforma, a través de la diferenciación y de la diversificación, en una pluralidad de interpretaciones, cuya finalidad es la de ofrecer a los individuos definiciones del mundo. Estas interpretaciones pretenden establecer identidades, libertad y emancipación respecto a las normatividades comunitarias y trascendentes. Surge en la modernidad, la 'religión a la carta'. Sin embargo, si algo permanece invariablemente constante en la vida diaria de las personas es, afirma Peter L. Berger, el temor a las situaciones marginales y a la anomia. Ni el proceso de secularización con sus universos simbólicos (filosofía diurna y teodiceas seculares), ni el resurgimiento religioso y global (desecularización público-política) han podido dar una explicación plausible y convincente de estos fenómenos que tanto afectan a la conciencia y a las identidades subjetivas de los individuos. En este sentido, y tras el fracaso de las anteriores cosmovisiones en su intento de dotar de sentido a la realidad y la vida ordinaria de las personas, Berger recurre a una nueva instauración del 'nomos religioso'. El desarrollo del concepto bergeriano de 'desecularización' está estrechamente ligado a lo que él denominó como la 'desecularización de la conciencia' en el ámbito del repliegue existencial del individuo, ante la crisis de sentido para, desde ahí, hacerse presente en el ámbito público como alternativa a los déficits colectivos de significado a través del siguiente itinerario: $1^{\circ}$ ) El individuo sufre una de-secularización de la conciencia debido a sus necesidades ontológicas, $2^{\circ}$ ) Posteriormente, y debido a la necesidad del individuo de dar sentido a nivel colectivo, se experimenta una desecularización pública como forma de satisfacer unas necesidades no ya ontológicas, sino psicológicas. Por tanto, es evidente que el concepto de 'desecularización' bergeriano nace desde una necesidad existencial de sentido y alcanza sus más altas 
metas en su despliegue en el ámbito de la teología, de la teodicea social y de la fenomenología de la religión, entre otras muchas entidades dotadoras de sentido ontológico.

Esta pretensión de Berger por resolver los problemas del ámbito teológico (principalmente en su última etapa, la etapa de la desecularización), mediante la operacionalización de su sociología de la religión le ha llevado a pasar de elaborar una sociología de la religión, con omnímodas pretensiones de ser una sociología cultural que dirige su atención al simbolismo intersubjetivo de la sociedad, a ser una 'sociología religiosa' de carácter reduccionista-apologético y con pretensiones de ser un encuentro entre sociología y teología. Esto se debe a que en Berger se mezclan continuamente su condición de científico social y su condición de cristiano. Ejemplo de ello es su última publicación Questions of faith (2004). Nos encontraríamos aquí muy próximos a las críticas de J. A. Prades y Von A. Harvey quienes consideraban que el razonamiento teórico bergeriano era más confesional que teológico (Prades) y, además, pretendía unificar la sociología con la teología (Harvey). Sin embargo, tres son los temas que es necesario resolver para determinar el carácter teológico que se instaura en la sociología bergeriana: $1^{\circ}$. El concepto de religión; $2^{\circ}$. El concepto de Dios; $2^{\circ}$. El concepto de teodicea.

El concepto de religión: Es difícil catalogar a Berger como sociólogo de la secularización o como sociólogo de la desecularización, del mismo modo que resulta difícil catalogarlo de funcionalista o de sustantivista al referirnos a su concepto de religión. Esto se debe a que Berger hace un uso 'caprichoso' de ambas concepciones con el fin de 'encajar' sus planteamientos teóricos dentro de un marco conceptual religioso que les confiera la legitimación necesaria. En este sentido, es curioso observar cómo en la década de los 60 (The sacred canopy), nuestro autor mantiene una polémica frente a los planteamientos funcionalistas luckmannianos en favor de una concepción sustantiva de la religión (teodiceas, alienación). De igual modo, podemos observar cómo en la década de los 70 (etapa secular) abandona la concepción sustantivista a favor de la funcionalista (adaptativa al proceso de secularización vigente) y, por último, a partir de la década de los noventa (etapa de la desecularización), vuelve a retomar el discurso sustantivista de la religión como ámbito de sentido existencial (teología, teodicea y escatología) con el consiguiente abandono de la concepción funcionalista.

El concepto de Dios: El concepto de Dios en Berger es algo que no queda nada claro a lo largo de su obra. Por un lado, nuestro autor defiende una concepción de Dios próxima al Dios bíblico, al Dios de los 
ejércitos, al Dios cruel que sacia su sed con la sangre de la cruz, un Dios próximo a los planteamientos de San Anselmo y Voltaire, un Dios muy próximo al Dios-nación que, últimamente, está legitimando toda la barbarie bélica e imperialista norteamericana y que se conoce con el apelativo de 'El Dios de Bush' (recordemos que Berger es un heredero de la 'teología del terror' de Rudolf Otto, donde la 'otra realidad' es concebida como una realidad impositiva para el hombre ante la cual sólo vale el sobrecogimiento). Por otro lado, Berger se refugia en el Dios de los místicos, el Dios escondido o Deus absconditus. Surge así, una paradoja que resulta de la imposibilidad de compatibilizar estas dos concepciones de Dios dentro de un mismo marco teórico que pretende ser global y universal. Ejemplo de este intento, por parte de Berger, de conciliar ambos conceptos es su pretensión de justificar a Dios a través del sufrimiento (teodiceas del sufrimiento). Surge la paradoja de conciliar al 'Dios sádico' de San Anselmo, al 'Dios del terror' de R. Otto, con el 'Dios amor' de Simone Weil, tres de sus grandes influencias teológicas. Esta paradoja nos permite poner en cuestión otra de las grandes aportaciones de Berger dentro de su teoría de la desecularización: su teodicea de raíz cristiana. Esto nos va a permitir determinar que el problema de Berger está en pretender resolver desde la sociología el problema de la teodicea. Es decir, Berger pretende conciliar el problema del mal en el mundo con la teodicea. Un problema que, por otro lado, se nos muestra del todo incompatible e imposible. Por tanto, una duda se nos plantea al estudiar la literatura religiosa $\mathrm{y}$, fundamentalmente, teológica de Berger: ¿Cuál es el Dios de Berger?

El concepto de teodicea: Es en la delimitación de su concepto de teodicea donde Berger manifiesta una ambigüedad que produce un mayor desconcierto. Es decir, por un lado, en sus obras primeras (década de los 60), Berger asume los postulados de Scheleirmacher, principalmente, y de los fenomenólogos de la religión (Otto y Eliade) para elaborar una teodiceización sin Dios. Es decir, una formulación donde el concepto de Dios es sustituido por la totalidad de la comunidad (colectividad social), por el carácter absoluto y panteísta de la realidad social construida colectivamente mediante un soporte legitimador que viene definido por la divinización de lo sobrenatural y lo trascendente, y donde la concepción explícita de Dios ni tan siquiera adopta la forma de impersonal, pues no tiene localización dentro de este desarrollo masoquista-misticista de aniquilación del 'yo'. Estamos, pues, ante la 'teodicea masoquista del sentimiento de dependencia del absoluto y de sumisión a los "totalmente otros". Por otro lado, en su obra de carácter teológico Questions of faith (2004), asume ahora los planteamientos 
weilianos y weberianos para elaborar unas 'estructuras de plausibilidad teodiceicas' donde la humanización de Dios (Dios sufre con el hombre) y la huída de este mundo (escatología) se presentan como categorías nómicas a través de las cuales pretende configurar un universo simbólico de sentido existencial. Por tanto, podemos observar cómo Berger pasa de elaborar una teodicea que pretende legitimar la ruptura ontológica entre el macrocosmos-microcosmos, mediante la divinización de lo humano (teología sin Dios), a elaborar una teodicea que pretende legitimar la ruptura ontológica entre lo trascendente-inmanente mediante la humanización de Dios (teología de la cruz). En este sentido, surge la siguiente pregunta: ¿Qué ha ocurrido en el pensamiento bergeriano para pasar de una teodicea masoquista donde Dios no tiene cabida y sólo se presenta como una realidad hipostasiada (relación con Feuerbach), donde el individuo no tiene tampoco ninguna representación activa a nivel individual, y donde el sentido es buscado y encontrado en la intersubjetividad de lo inmediato y lo inmanente; a pasar a una teodicea donde Dios (personal y trascendente) es el pilar fundamental de esta construcción de la realidad —en detrimento de la colectividad social-, donde el individuo adquiere un protagonismo activo en la búsqueda de lo divino (representado por Dios) en la forma de una teología inductiva, y donde el sentido no puede ser ya encontrado en este mundo inmediato y presente, sino en la futuridad y en el determinismo que nos debe ser dado y revelado (parousia, escatología). A raíz de esta pregunta, surgen otras muchas que ponen de manifiesto la ambigüedad y el desconcierto que Berger provoca en los estudiosos de su pensamiento. Algunas de estas preguntas aclaratorias podrían ser: $1^{\circ}$. ¿Qué ha hecho a Berger pasar de una actitud teodiceico-masoquista sin Dios a una concepción de Dios teodiceico-masoquista?; $2^{\circ}$. ¿Echa por tierra, la aparición de Dios, toda su anterior teodicea y todo el andamiaje del 'nomos religioso tradicional' que había sido legitimado dentro de una concepción religiosa sin Dios y cuya divinidad venía representada por el carácter sagrado y sobrenatural-trascendente de la realidad socialmente construida?; $3^{\circ}$. ¿Es tan importante ahora la figura de Dios que sin ella sería imposible adaptar el 'nomos religioso tradicional' a las circunstancias actuales de crisis de sentido, como marco legitimador?; $4^{\circ}$. ¿Es Dios el elemento clave de su teoría de la desecularización, pues sin él su 'nomos religioso tradicional' quedaría totalmente obsoleto en un mundo moderno donde se ha demostrado que la pretendida divinización del hombre y la hipostatización de la idea de Dios como 'teología ajena' no ha servido para resolver la crisis de sentido?; $5^{\circ}$. ¿Es la idea de Dios la que hace pasar a Berger de la 'fe en el sistema' a la 'fe escatológica'?; y por último, $6^{\circ}$. ¿Es la fusión entre teología y teodicea la única salida al problema? 
Cuando en el año 2003 salió a la luz mi trabajo: El problema de la identidad religiosa en la modernidad tardía: Secularización y pluralismo según Peter L. Berger, abrí unas posibles líneas de investigación en torno al pensamiento de este autor. Entre estas líneas, puse el acento en indagar sobre las aportaciones de Berger a temáticas de encuentro entre la sociología de la religión y los problemas sociales actuales que marcan y determinan la configuración de las identidades religiosas. Estas posibles temáticas de investigación futura, se centraban en descubrir al Berger sociólogo y al Berger científico social, fundamentalmente. A lo largo de estos años he descubierto al Berger teólogo, al Berger de la teodicea, al Berger sereno frente al impetuoso ideólogo de los años sesenta y setenta. Hoy me doy cuenta de que conocemos mucho de la sociología (sociología del conocimiento y de la religión) bergeriana, pero muy poco de la propuesta que desde la teología y desde la teodicea nos brinda este autor.

\section{REFERENCIAS}

-Hunter, J. D. (1987). Cultural Analysis. London: Routledge and Kegan Paul.

-Baum, G. (1980). Religión y alienación. Madrid: Cristiandad.

-Berger, P. (1967). The sacred canopy: Elements of a sociological theory of religion. Garden City, N.Y: Doubleday.

-Berger, P. \& Luckmann, Th. (1966). The social construction of reality: A treatise in the sociology of knowledge. Garden City, N.Y: Doubleday.

-Berger, P. (1969). A rumor of angels: Modern society and the rediscovery of the supernatural. Garden City, N.Y: Doubleday.

-Berger, P. (1992). A far glory: The quest for faith in an age of credulity. New York: Free Press.

-Berger, P. (Ed.) (1999). The desecularization of the world: Resurgent religion and world politics. Washington: Ethics and the Public Policy Center and Wm. B. Eerdmans Publisihing Co.

-Berger, P. (2003). Questions of faith. A skeptical affirmation of Christianity. Oxford: Blackwell Publishing.

-Feuerbach, L. (1975). La esencia del cristianismo. Salamanca: Sígueme.

-Freud, S. (1981). El porvenir de una ilusión. En Obras completas (17 Vols.). Madrid: Biblioteca Nueva.

-Fromm, E. (1969). Psicoanálisis y religión. Buenos Aires: Edit. Psique.

-Marx, K. (1979). Tesis sobre Feuerbach. En Sobre la religión (Vol. I). Salamanca: Sígueme.

-Pannenberg, W. (1976). Tipos de ateísmo y su significación teológica. En Cuestiones fundamentales de teología sistemática. Salamanca: Sígueme.

-Rubio Ferreres, J. M. (1988). ¿Resurgimiento religioso versus secularización? Gazeta de Antropología (14). 
-Schleiermacher, F. D. E. (1990). Sobre la religion. Madrid: Tecnos.

-Woodhead, L. (Ed.) (2001). Peter Berger and the study of religion. London: Routledge.

Sumario: Introducción; 1. Las influencias teológicas; 2. Religión e identidad socio-existencial: la necesidad de legitimaciones religiosas; 3. Alienación, teología de la inmanencia y fundamentación antropológica; Conclusiones; Referencias. 